\title{
Article
}

\section{S1P Increases VEGF Production in Osteoblasts and Facilitates Endothelial Progenitor Cell Angiogenesis by Inhibiting miR-16-5p Expression via the c-Src/FAK Signaling Pathway in Rheumatoid Arthritis}

\author{
Chien-Chung Huang 1,2 ${ }^{(D)}$, Tzu-Ting Tseng ${ }^{1}$, Shan-Chi Liu ${ }^{3}$, Yen-You Lin ${ }^{1}$, Yat-Yin Law ${ }^{4,5}$, Sung-Lin Hu ${ }^{1,6}$, \\ Shih-Wei Wang $7,8,9$ (D) Chun-Hao Tsai ${ }^{10,11, * \mathbb{D}}$ and Chih-Hsin Tang 1,12,13,*(D)
}

1 School of Medicine, China Medical University, Taichung 40402, Taiwan; cchuang10127@mail.cmu.edu.tw (C.-C.H.); cawaii7992@gmail.com (T.-T.T.); chas6119@gmail.com (Y.-Y.L.); nick07202011@yahoo.com.tw (S.-L.H.)

2 Division of Immunology and Rheumatology, Department of Internal Medicine, China Medical University Hospital, Taichung 40402, Taiwan

3 Department of Medical Education and Research, China Medical University Beigang Hospital, Yunlin 65152, Taiwan; sdsaw.tw@yahoo.com.tw

4 Institute of Medicine, Chung Shan Medical University, Taichung 40201, Taiwan; andrewlaw@gmail.com

5 Department of Orthopedics, Chung Shan Medical University Hospital, Taichung 40201, Taiwan

Citation: Huang, C.-C.; Tseng, T.-T.; Liu, S.-C.; Lin, Y.-Y.; Law, Y.-Y.; Hu, S.-L.; Wang, S.-W.; Tsai, C.-H.; Tang, C.-H. S1P Increases VEGF Production in Osteoblasts and Facilitates Endothelial Progenitor Cell Angiogenesis by Inhibiting miR-16-5p Expression via the c-Src/FAK Signaling Pathway in Rheumatoid Arthritis. Cells 2021, 10, 2168. https://doi.org/10.3390/ cells10082168

Academic Editor: Richard O. Williams

Received: 21 July 2021

Accepted: 18 August 2021

Published: 23 August 2021

Publisher's Note: MDPI stays neutral with regard to jurisdictional claims in published maps and institutional affiliations.

Copyright: () 2021 by the authors. Licensee MDPI, Basel, Switzerland. This article is an open access article distributed under the terms and conditions of the Creative Commons Attribution (CC BY) license (https:// creativecommons.org/licenses/by/ $4.0 /)$.
6 Department of Family Medicine, China Medical University Hsinchu Hospital, Hsinchu 30210, Taiwan

7 Institute of Biomedical Sciences, Mackay Medical College, New Taipei City 25245, Taiwan; shihwei@mmc.edu.tw

8 Department of Medicine, Mackay Medical College, New Taipei City 25245, Taiwan

9 Graduate Institute of Natural Products, College of Pharmacy, Kaohsiung Medical University, Kaohsiung 80708, Taiwan

10 Department of Sports Medicine, College of Health Care, China Medical University, Taichung 40402, Taiwan

11 Department of Orthopedic Surgery, China Medical University Hospital, Taichung 40402, Taiwan

12 Chinese Medicine Research Center, China Medical University, Taichung 40402, Taiwan

13 Department of Biotechnology, College of Health Science, Asia University, Taichung 40354, Taiwan

* Correspondence: ritsai8615@gmail.com (C.-H.T.); chtang@mail.cmu.edu.tw (C.-H.T.); Tel.: +886-4-22052121 (ext. 5052) (C.-H.T.); +886-4-22052121 (ext. 7726) (C.-H.T.)

\begin{abstract}
Angiogenesis is a critical process in the formation of new capillaries and a key participant in rheumatoid arthritis (RA) pathogenesis. Vascular endothelial growth factor (VEGF) stimulation of endothelial progenitor cells (EPCs) facilitates angiogenesis and the progression of RA. Phosphorylation of sphingosine kinase 1 (SphK1) produces sphingosine-1-phosphate (S1P), which increases inflammatory cytokine production, although the role of S1P in RA angiogenesis is unclear. In this study, we evaluated the impact of S1P treatment on VEGF-dependent angiogenesis in osteoblast-like cells (MG-63 cells) and the significance of SphK1 short hairpin RNA (shRNA) on S1P production in an in vivo model. We found significantly higher levels of S1P and VEGF expression in synovial fluid from RA patients compared with those with osteoarthritis by ELISA analysis. Treating MG63 cells with S1P increased VEGF production, while focal adhesion kinase (FAK) and Src siRNAs and inhibitors decreased VEGF production in S1P-treated MG-63 cells. Conditioned medium from S1P-treated osteoblasts significantly increased EPC tube formation and migration by inhibiting miR16-5p synthesis via proto-oncogene tyrosine-protein kinase src (c-Src) and FAK signaling in chick chorioallantoic membrane (CAM) and Matrigel plug assays. Infection with SphK1 shRNA reduced angiogenesis, articular swelling and cartilage erosion in the ankle joints of mice with collagen-induced arthritis (CIA). S1P appears to have therapeutic potential in RA treatment.
\end{abstract}

Keywords: S1P (sphingosine-1-phosphate); vascular endothelial growth factor; osteoblasts; rheumatoid arthritis 


\section{Introduction}

Angiogenesis is a critical driver of rheumatoid arthritis (RA) development [1], as are endothelial progenitor cells (EPCs) [2,3], which contain the cell surface markers CD34, CD133 and vascular endothelial growth factor receptor 2 (VEGFR2), which stimulate postnatal vasculogenesis [4] and angiogenic function [5]. VEGF induces EPC proliferation and migration, and facilitates angiogenesis [5], enabling the development of RA [6,7]. We have previously demonstrated that the proinflammatory cytokine cysteine-rich 61 (CCN1) stimulates VEGF expression in osteoblasts and upregulates EPC angiogenesis in RA [7]. EPC-dependent angiogenesis therefore seems to be a worthwhile treatment target in RA.

The platelet-derived lysophospholipid mediator sphingosine-1-phosphate (S1P) inhibits platelet-derived growth factor-promoted chemotaxis and activates cellular Rasrelated C3 botulinum toxin substrate (Rac), which are implicated in RA pathogenicity [8]. Various biologic functions that are regulated by the S1P/S1P receptor axis include tumor invasiveness and progression, angiogenesis, vasculogenesis, skeletal muscle and nervous system degeneration [9-11]. Research has revealed that $\mathrm{S} 1 \mathrm{P} / \mathrm{S} 1 \mathrm{P}$ receptor $1\left(\mathrm{~S}_{1} \mathrm{P}_{1}\right)$ signaling can regulate osteoimmunology [12], and the S1P receptor is upregulated in synovial tissue from the collagen-induced arthritis (CIA) mouse model [13]. Proangiogenic factors can stimulate the sphingosine kinase $1(\mathrm{SphK} 1) / \mathrm{S} 1 \mathrm{P} / \mathrm{S}_{1} \mathrm{P}_{1}$ pathway to upregulate fibroblast-like synoviocyte (FLS) proliferation and migration and facilitate angiogenesis in a rat model of RA [14]. Moreover, inflammation induction increases in $\mathrm{S} 1 \mathrm{P} / \mathrm{S}_{1} \mathrm{P}_{3}$ signaling and stimulates increased production of interleukin (IL)-6 in FLSs from CIA mice [13]. We have previously shown that S1P upregulates the expression of IL-1 $\beta$ and IL-6 in human osteoblasts $[15,16]$, which suggests that $\mathrm{S} 1 \mathrm{P}$ may serve as an inflammatory mediator during arthritis progression.

Osteoblasts are important in RA cartilage pathology $[7,17]$. The secretion of proinflammatory cytokines by osteoblasts facilitates RA development [17,18], and upregulated IL-17 expression in osteoblasts triggers the migration of monocytes in RA disorders [19]. In addition, osteoblast-synthesized VEGF enhances EPC angiogenesis during RA progression [7], while we have previously demonstrated that S1P stimulates IL-1 $\beta$ production through the JAK and STAT3 signaling pathways in osteoblasts [20], and the S1P/S1P receptor axis reportedly promotes cyclooxygenase-2 and prostaglandin E2 in RA [21]. Previous research has shown that microRNAs (miRNAs) regulate the progression of RA [22,23], and we have reported miRNA involvement in inflammation and angiogenesis $[16,24,25]$. Notably, S1P can regulate miRNA expression in human disorders such as cancer and rheumatic disease [26-28]. However, research has yet to clarify the role of S1P in RA angiogenesis. Our study has identified higher S1P and VEGF expression in patients with RA than those with osteoarthritis (OA). S1P treatment increased the production of osteoblast-derived VEGF and facilitated EPC-driven angiogenesis by blocking miR-16-5p synthesis through the c-Src/FAK signaling pathway. Inhibition of S1P expression diminished VEGF-dependent angiogenesis and reduced CIA in mice. S1P is therefore worth targeting in RA.

\section{Materials and Methods}

\subsection{Materials}

Antibodies against the phosph- FAK (catalog number: sc-374668) and c-Src (catalog number: SC-12928-R), total protein of c-Src (catalog number: SC-5266) and FAK (catalog number: SC-1688), VEGF (catalog number: SC-7269), SphK1 (catalog number: sc-365401) and $\beta$-actin (catalog number: sc-47778) were bought from Santa Cruz Biotechnology (Dallas, TX, USA). Small interfering RNAs were obtained from Dharmacon ${ }^{\mathrm{TM}}$ (Lafayette, CO, USA). Control mimic and miRNA mimic were provided by Thermo Fisher Scientific (Waltham, MA, USA). The TaqMan ${ }^{\circledR}$ MicroRNA Reverse Transcription Kit, qPCR primers and detection probes were all obtained from Applied Biosystems (Waltham, MA, USA). The Src inhibitor (10 $\mu \mathrm{M}$ PP2, catalog number: P0042) was supplied by Sigma-Aldrich (St. Louis, MO, USA) and the FAK inhibitor (10 $\mu \mathrm{M}$ FAKi, catalog number: 324878$)$ by Calbiochem (San Diego, CA, USA). 


\subsection{The Collection of Synovial Fluids}

The study was granted approval by the Institutional Review Board (IRB) of China Medical University Hospital (CMUH, Taichung, Taiwan). Each patient provided written informed consent before participating in the research. Synovial fluid samples were collected during total knee arthroplasty.

\subsection{Cell Culture}

Human osteoblast-like cells (MG-63) were purchased from the American Type Cell Culture (ATCC, Manassas, VA, USA) and cultured in Eagle's Minimum Essential Medium (MEM) supplemented with $50 \mathrm{U} / \mathrm{mL}$ penicillin, $50 \mu \mathrm{g} / \mathrm{mL}$ streptomycin and $10 \%$ fetal bovine serum (FBS), then maintained in a cell culture incubator at $37{ }^{\circ} \mathrm{C}$ in $5 \% \mathrm{CO}_{2}$. Human EPCs were isolated and cultured following the method detailed in our published reports [29,30].

\subsection{Immunoblotting Analysis}

Cell lysates were separated by $8-10 \%$ SDS-PAGE and transferred onto Immobilon ${ }^{\circledR}$ PVDF membranes (Millipore, Billerica, MA, USA). Immunoblotting data are shown according to the procedures detailed in our past investigations [31-33].

\subsection{Quantitative Real-Time PCR ( $q P C R)$ Analysis}

TRIzol $^{\circledR}$ reagent (MDBio Inc., Taipei, Taiwan) was used to extract RNA from the osteoblasts and the oligo $(\mathrm{dT})$ primers were used to reverse transcribe messenger RNA (mRNA) to complementary DNA (cDNA). SYBR ${ }^{\mathrm{TM}}$ Green Master Mix (Applied Biosystems, Waltham, MA, USA) was used for real-time quantitative polymerase chain reaction (qPCR) analysis. [34-36]. The real-time PCR oligo(dT) primers used for genotyping were as follows: VEGF (forward), 5'-AGGGCAGAATCATCACGAAGT'; VEGF (reverse), 5' AGGGTCTCGATTGGATGGCA-3'; GAPDH (forward), 5'-ACCACAGTCCATGCCATCAC -3'; GAPDH (reverse), 5'-TCCACCACCCTGTTGCTGTA-3'; miR-16-5p, 5'-TAGCAGCACG TAAATATTGGCG -3'; U6 (forward), 5'-CGCTTCGGCAGCACATATAC-3; U6 (reverse), 5'-AAAATATGGAACGCTTCACGA-3'.

\subsection{ELISA Assay}

S1P and VEGF expression in the synovial fluid of patients was quantified by an ELISA kit (R\&D Systems, Inc., Minneapolis, MN, USA). Conditioned medium (CM) was collected from the osteoblasts after $24 \mathrm{~h}$ of S1P treatment and quantified for VEGF expression using the ELISA kit, following the manufacturer's instructions.

\subsection{EPC Migration and Tube Formation}

Migration activity was examined by Transwell plates ( $8 \mu \mathrm{M}$ pores) (Costar/Corning, Lowell, MA, USA). We seeded $1 \times 104$ EPCs into the upper chamber in $200 \mu \mathrm{L}$ of $10 \% \mathrm{FBS}$ in MV2 complete medium. The lower chamber contained $150 \mu \mathrm{L}$ of $20 \%$ FBS in MV2 complete medium and $150 \mu \mathrm{L} \mathrm{CM}$. After $24 \mathrm{~h}$, cells were fixed in 3.7\% formaldehyde solution and stained with crystal violet $(0.05 \%)$ for $15 \mathrm{~min}$. Cells on the upper side of the filters were removed and washed with PBS. Cells on the undersides of the filters were examined and counted under microscope (200x magnification) (Nikon H600L, Nikon, Tokyo, Japan). Each clone was plated three times for each experiment, and each experiment was repeated at least three times [37]. Tube formation methodology followed our previous research [37]. Matrigel (BD Biosciences, Bedford, MA, USA) was dissolved at $4{ }^{\circ} \mathrm{C}$, then added at a concentration of $200 \mu \mathrm{L}$ to each well of 24 -well plates and incubated at $37^{\circ} \mathrm{C}$ for $15 \mathrm{~min}$. Briefly, EPCs were resuspended in MV2 serum-free medium and mixed with CM from the S1P-treated MG63 cells, then added to the wells. After 6-8 h of incubation at $37^{\circ} \mathrm{C}$, EPC tube formation was examined by microscopy. Briefly, this examination focused on 5 areas that were dense with active tube formation. For the migration and tube formation assays, VEGF protein ( $5 \mu \mathrm{g} / \mathrm{mL}$ ) (R\&D Systems, Inc., Minneapolis, MN, USA) was used 
as a positive control and IgG protein $(5 \mu \mathrm{g} / \mathrm{mL}$ ) (R\&D Systems, Inc., Minneapolis, MN, USA) as a negative control; VEGF antibody $(5 \mu \mathrm{g} / \mathrm{mL}$ ) (R\&D Systems, Inc., Minneapolis, MN, USA) was used to reduce S1P-induced increases in VEGF protein expression. Tube branches and tube lengths were examined at a magnification of 20x and calculated with MacBiophotonics ImageJ software.

\subsection{Transfection of Small Interfering RNAs and miRNA Mimic}

MG63 cells were transfected with siRNAs (control, S1P1, S1P3, FAK, Src) or miR-16-5p mimic for $24 \mathrm{~h}$ using Lipofectamine 2000 (Invitrogen, Waltham, MA, USA), as described in our previous study [38].

\subsection{The Chick Chorioallantoic Membrane Assay}

The chicken chorioallantoic membrane (CAM) system assessed angiogenic activity, as described previously $[7,39]$. Fertilized chick embryos were incubated in an $80 \%$ humidified atmosphere at $37^{\circ} \mathrm{C}$.

\subsection{Matrigel Plug Assay}

For the Matrigel plug assay, we used 10 mice in each group and subcutaneously injected them with $0.2 \mathrm{~mL}$ Matrigel mixture consisting of 50\% CM from S1P-treated MG63 cells and 50\% Matrigel. After 7 days, we harvested the Matrigel plugs and measured the hemoglobin concentrations, according to previously described methodology $[7,18,39]$.

\subsection{CIA Mouse Model}

CIA immunization was performed according to the methodology detailed in our previous publications $[7,16,18]$. After receiving two immunizations, the mice received weekly intra-articular injections of $\sim 7.1 \times 10^{6}$ plaque-forming units (PFU) of SphK1 short hairpin RNA (shRNA) or control. Upon sacrifice after 49 days of treatment, phalanges and ankle joints were collected from each mouse then stored in $4 \%$ paraformaldehyde for micro-computed tomography $(\mu-\mathrm{CT})$ scanning.

\subsection{Statistical Analysis}

All statistical analyses were performed using GraphPad Prism 5.0 (GraphPad Software, San Diego, CA, USA) and all values are presented as the mean \pm standard deviation (S.D.). The paired sample $t$-test was used for in vitro analyses of statistical significance; one-way ANOVA followed by Bonferroni testing was used for in vivo analyses.

\section{Results}

\subsection{Upregulation of S1P and VEGF Expression in RA}

Markedly higher levels of S1P and VEGF expression were identified in samples of RA synovial fluid than in OA samples (Figure 1A,B), suggesting that S1P and VEGF are more critical in RA than in OA.

\subsection{S1P Facilitates VEGF-Dependent EPC Angiogenesis}

Next, we examined whether S1P promotes osteoblastic VEGF expression. Incubation of MG-63 cells with S1P dose-dependently increased VEGF transcription and translation (Figure 2A,B) and the secretion of VEGF protein (Figure 2C). EPC tube formation and migration assays illustrated the effects of S1P-controlled angiogenesis in osteoblasts [6]. CM from S1P-treated MG63 cells significantly increased capillary-like network formation and reorganization as well as EPC migratory activity (Figure 2D,E). Treatment with VEGF antibody dramatically diminished the effects of S1P-treated osteoblast CM on EPC tube formation and migration (Figure 2D,E), indicating that S1P promotes VEGF production in osteoblasts and enhances tube formation and migration of EPCs. 
(A)

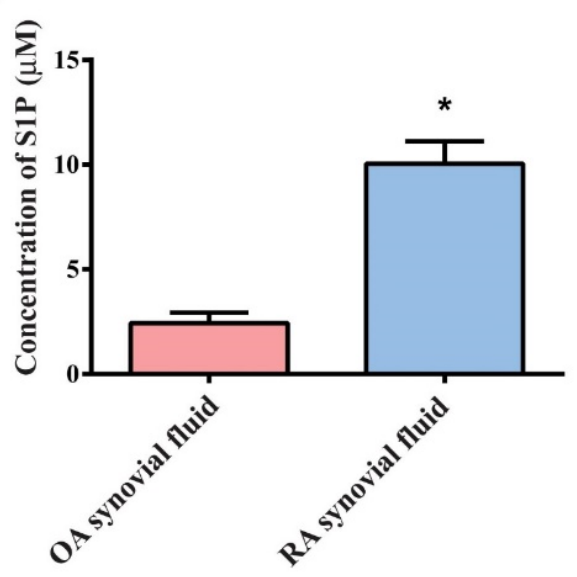

(B)

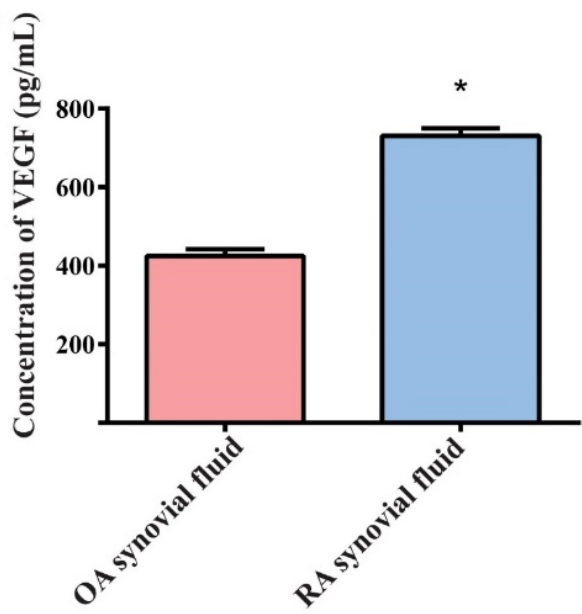

Figure 1. Upregulation of S1P and VEGF expression in RA. S1P (A) and VEGF (B) levels in human $\mathrm{OA}$ and RA synovial fluid were quantified by ELISA. Results are expressed as the mean \pm S.D. $(n=4) .{ }^{*} p<0.05$ versus the OA group.

(A)

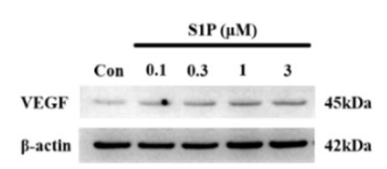

(B)

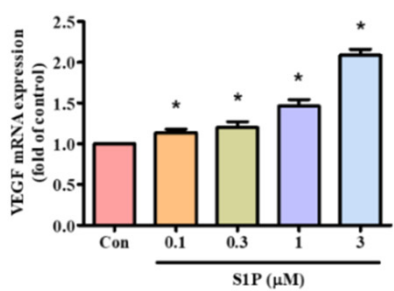

(C)

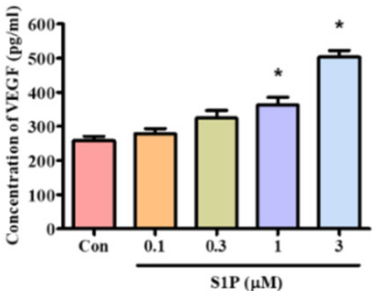

(D)
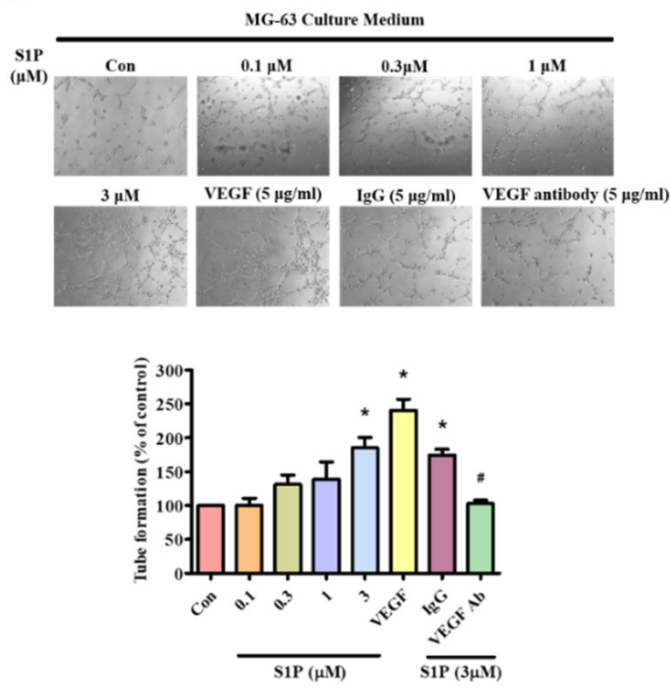

(E)
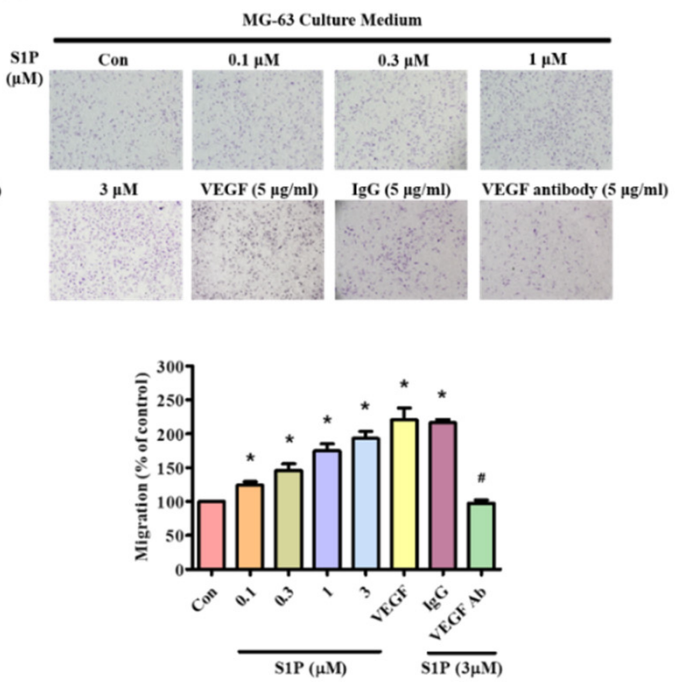

Figure 2. S1P increases osteoblastic VEGF expression and promotes EPC tube formation and migration. (A-C) MG-63 cells were incubated for $24 \mathrm{~h}$ with S1P $(0.1-3 \mu \mathrm{M})$; VEGF expression was quantified by Western blot, qPCR and ELISA. (D,E) Collected conditioned medium (CM) was administered to endothelial progenitor cells (EPCs), then EPC angiogenesis was measured by tube formation and the Transwell assay. Results are expressed as the mean \pm S.D. $(n=3)$. VEGF protein $(5 \mu \mathrm{g} / \mathrm{mL})$ was used as a positive control and $\operatorname{IgG}$ protein $(5 \mu \mathrm{g} / \mathrm{mL})$ as a negative control; VEGF antibody $(5 \mu \mathrm{g} / \mathrm{mL})$ was used to against VEGF protein expression. ${ }^{*} p<0.05$ versus the control; $\# p<0.05$ versus S1P alone. 


\subsection{S1P Enhances VEGF-Dependent EPC Angiogenesis through the $\mathrm{S1P}_{1} / \mathrm{S}_{\mathrm{P}} \mathrm{P}_{3}$ Receptor, $\mathrm{c}$-Src and FAK Pathways}

$\mathrm{S}_{1} \mathrm{P}_{1} / \mathrm{S}_{1} \mathrm{P}_{3}$ receptor signaling regulates the participation of $\mathrm{S} 1 \mathrm{P}$ in different cellular functions $[9,40]$. Transfection of osteoblasts with $\mathrm{S}_{1} \mathrm{P}_{1}$ or $\mathrm{S}_{1} \mathrm{P}_{3}$ siRNAs antagonized the effects of S1P on VEGF expression (Figure 3). Thus, the $\mathrm{S}_{1} \mathrm{P}_{1}$ and $\mathrm{S}_{1} \mathrm{P}_{3}$ receptors mediate the impact of S1P on VEGF production. c-Src and FAK signaling controls different cellular functions, including angiogenesis [29,39]. We therefore sought to determine how c-Src and FAK affect S1P-induced upregulation of VEGF synthesis and angiogenesis. Treatment of osteoblasts with c-Src (PP2) and FAK inhibitors or siRNAs for $24 \mathrm{~h}$ reduced the effects of S1P on VEGF mRNA and protein (Figure 4A,B) and inhibited S1P-induced upregulation of EPC tube formation and migration (Figure 4C,D). Transfecting the osteoblasts with c-Src and FAK siRNAs reduced c-Src and FAK expression (Figure 4E), while incubating the osteoblasts with S1P induced c-Src and FAK phosphorylation (Figure 4F). The c-Src inhibitor reversed S1P-induced promotion of c-Src and FAK phosphorylation (Figure 4G,H), whereas the FAK inhibitor did not affect S1P-mediated c-Src phosphorylation, which suggests that S1P promotes VEGF expression and EPC angiogenesis by modulating the c-Src and FAK signaling pathway.

\subsection{Inhibiting miR-16-5p Controls S1P-Promoted VEGF Synthesis and EPC Angiogenesis}

The dysregulated expression of miRNAs in patients with RA differs from miRNA expression in healthy individuals [41,42]. Using open-source software, we identified 20 miRNAs that potentially interfere with VEGF transcription (Figure 5A). S1P treatment of osteoblasts reduced miR-16-5p synthesis in a concentration-dependent manner (Figure 5B), while transfecting osteoblasts with miR-16-5p mimic antagonized the effects of S1P on VEGF production and EPC angiogenesis (Figure 5C-F). To examine whether miR-16-5p regulates VEGF gene transcription, we constructed luciferase reporter plasmids harboring either the wild-type $3^{\prime}$ UTR of VEGF mRNA (wt-VEGF-3'UTR) or a vector containing mismatches in the predicted miR-16-5p binding site (mt-VEGF-3'UTR) (Figure 5G). MiR16-5p mimic reduced S1P-induced luciferase report activity in the wild-type plasmid only (Figure $5 \mathrm{H}$ ). Moreover, the $\mathrm{S}_{1} \mathrm{P}_{1}$ and $\mathrm{S} \mathrm{P}_{3}$ siRNAs, as well as the c-Src and FAK inhibitors, all reversed S1P-induced inhibition of miR-16-5p expression (Figure 5I).

(A)

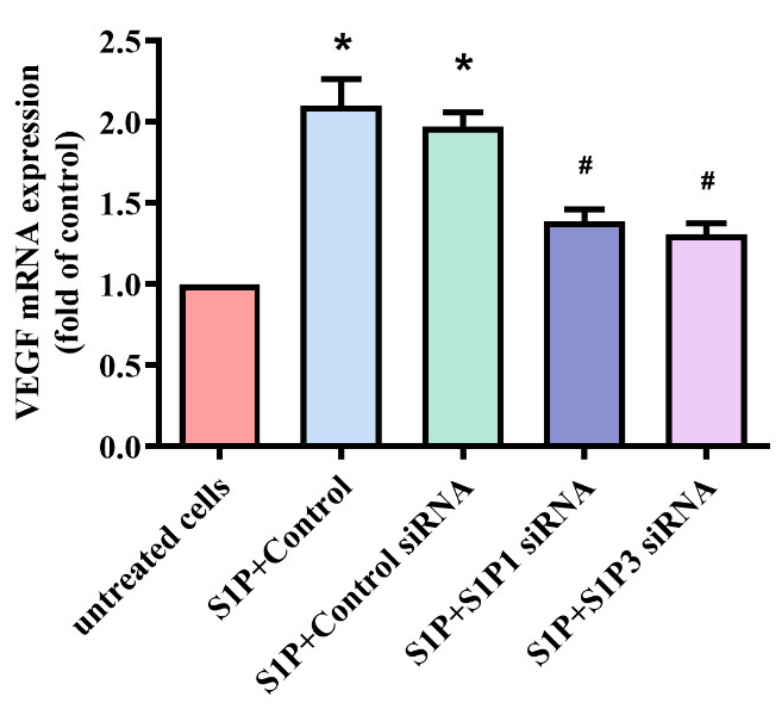

(B)

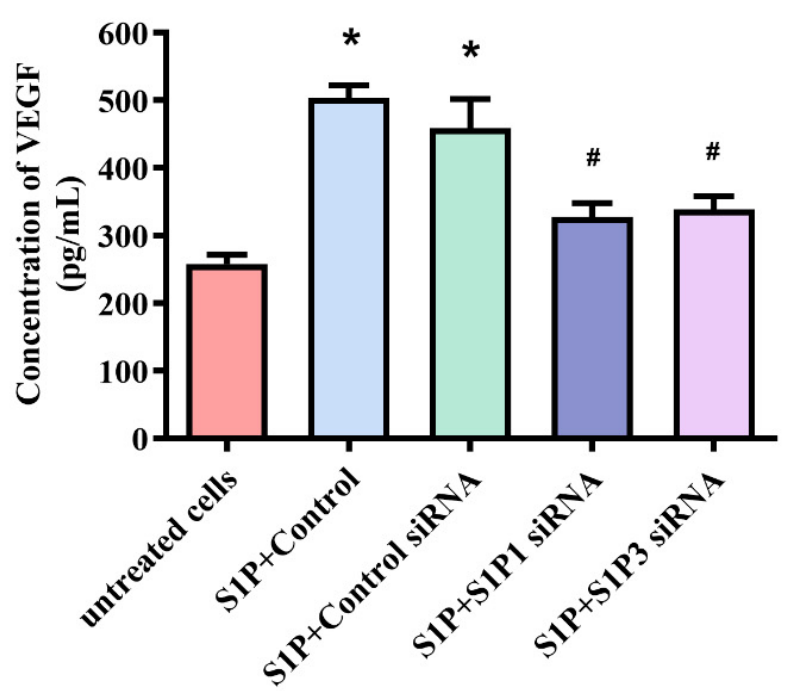

Figure 3. The $\mathrm{S}_{1} \mathrm{P}_{1}$ and $\mathrm{S}_{1} \mathrm{P}_{3}$ receptors control S1P-induced upregulation of VEGF expression. Osteoblasts were transfected with $\mathrm{S}_{1} \mathrm{P}_{1}$ or $\mathrm{S}_{3} \mathrm{P}_{3}$ siRNAs, before being stimulated with S1P. VEGF levels were quantified by qPCR (A) and ELISA (B) assays. Results are expressed as the mean \pm S.D. $(n=3) .{ }^{*} p<0.05$ versus the control; $\# p<0.05$ versus S1P alone. 
(A)
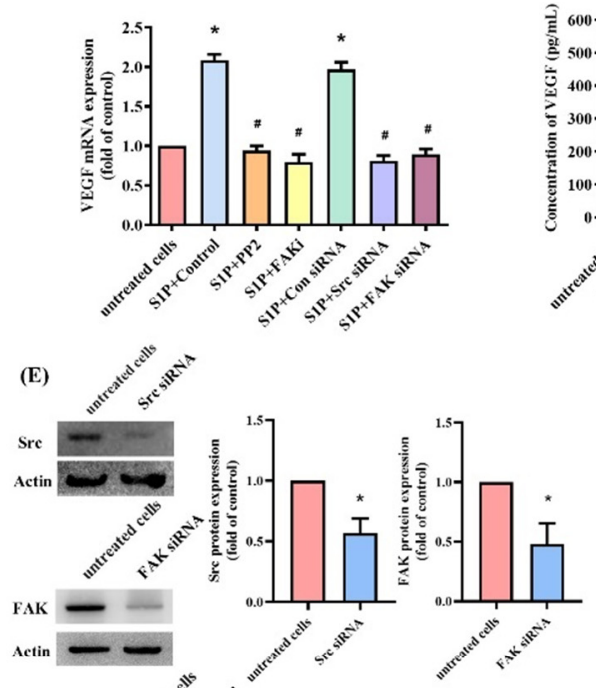

(G)
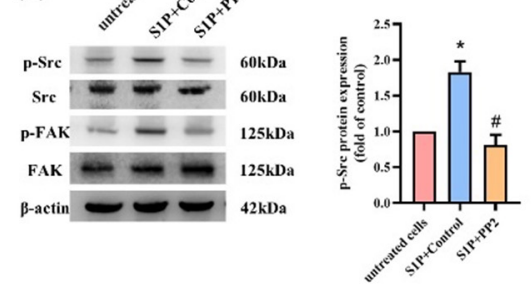

(B)

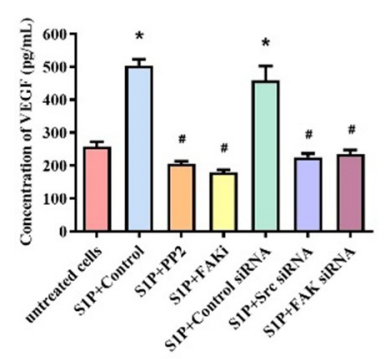

(C)

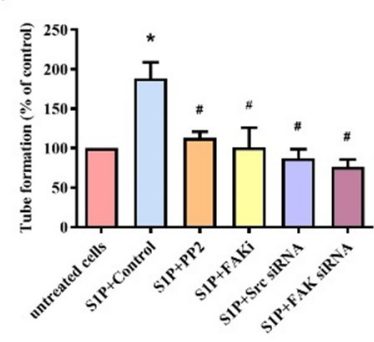

(D)

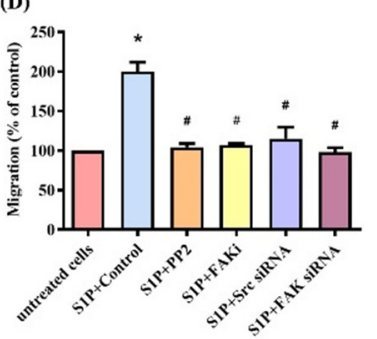

(F)
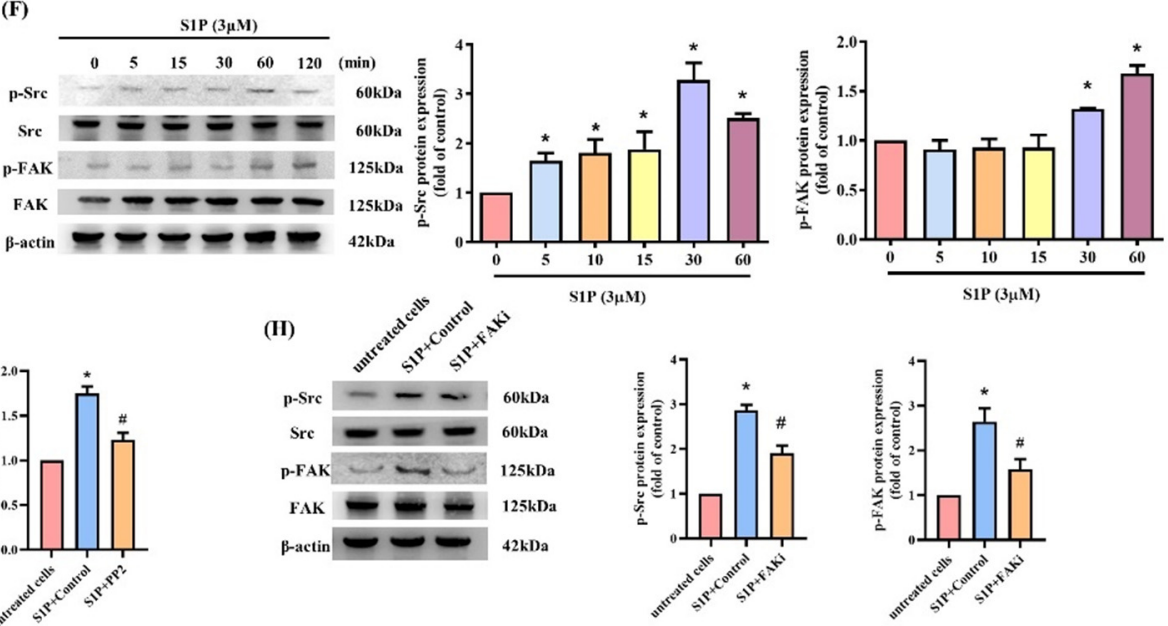

Figure 4. c-Src-dependent FAK activation regulates S1P-induced effects on VEGF production and EPC angiogenesis. (A,B) Osteoblasts were pretreated with c-Src (PP2) $(10 \mu \mathrm{M})$ or FAK inhibitors $(10 \mu \mathrm{M})$, or transfected with siRNAs (c-Src or FAK), then stimulated with S1P. VEGF levels were quantified by qPCR and ELISA. (C,D) Collected CM was administered to EPCs, and EPC angiogenesis was determined. (E) Osteoblasts were transfected with c-Src or FAK siRNAs and Western blot determined c-Src or FAK expression. (F) After incubating osteoblasts with S1P, Western blot determined c-Src and FAK phosphorylation. $(\mathbf{G}, \mathbf{H})$ Osteoblasts were pretreated with c-Src (PP2) $(10 \mu \mathrm{M})$ or FAK inhibitors $(10 \mu \mathrm{M})$, then stimulated with S1P. Western blot quantified c-Src and FAK phosphorylation and total protein. Results are expressed as the mean \pm S.D. $(n=3) .{ }^{*} p<0.05$ versus the control; $\# p<0.05$ versus S1P alone.

CAM and Matrigel investigations demonstrated that CM from S1P-treated osteoblasts enhanced vessel formation in vivo (Figure 6A,B), while the c-Src and FAK inhibitors, and miR-16-5p mimic, diminished S1P-promoted induction of vessel formation (Figure 5A,B). The results were confirmed by levels of hemoglobin and the human-specific vessel marker CD31, as well as by VEGF IHC staining (Figure 6C). 
(A)

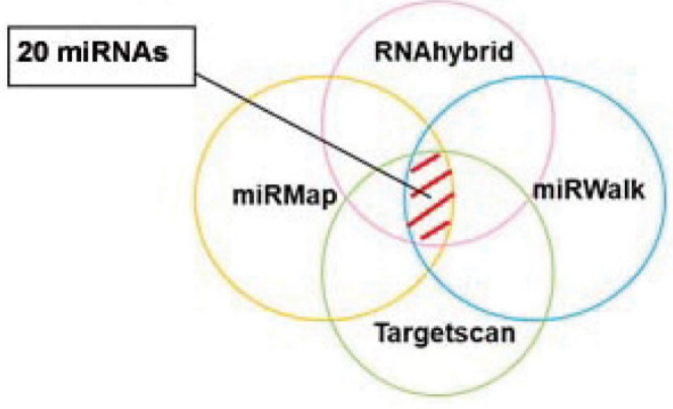

(D)

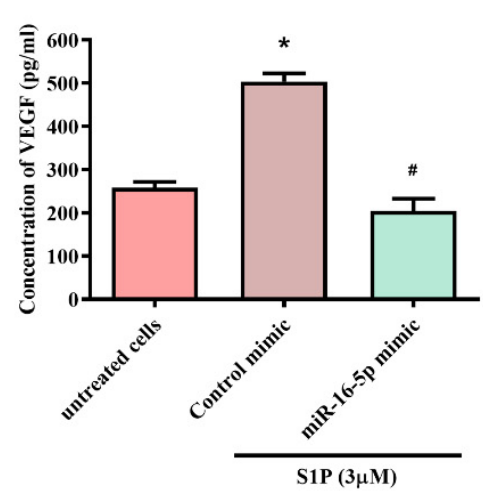

(G)

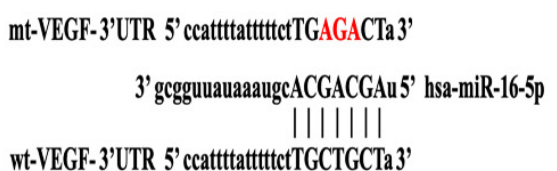

(B)

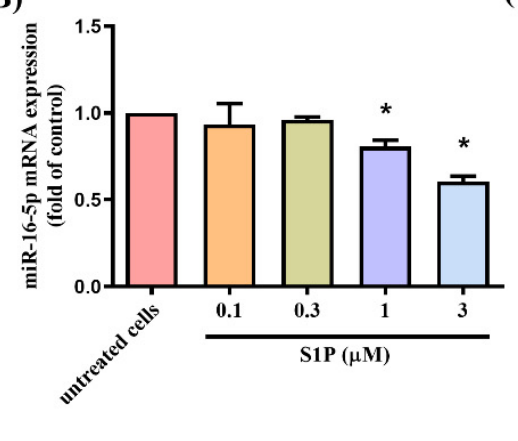

(E)

(H)
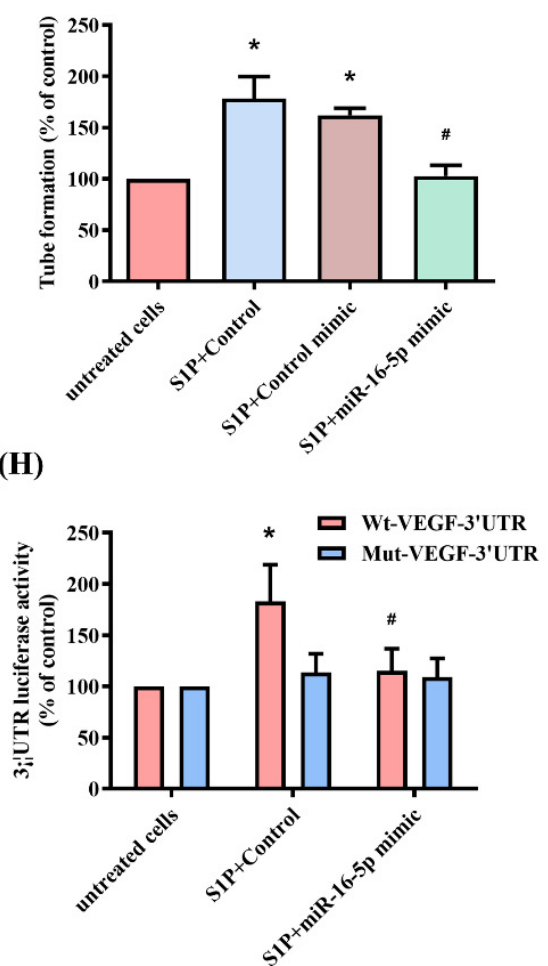

(C)

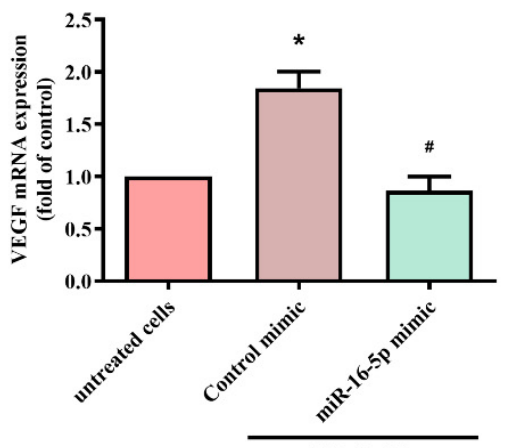

(F)
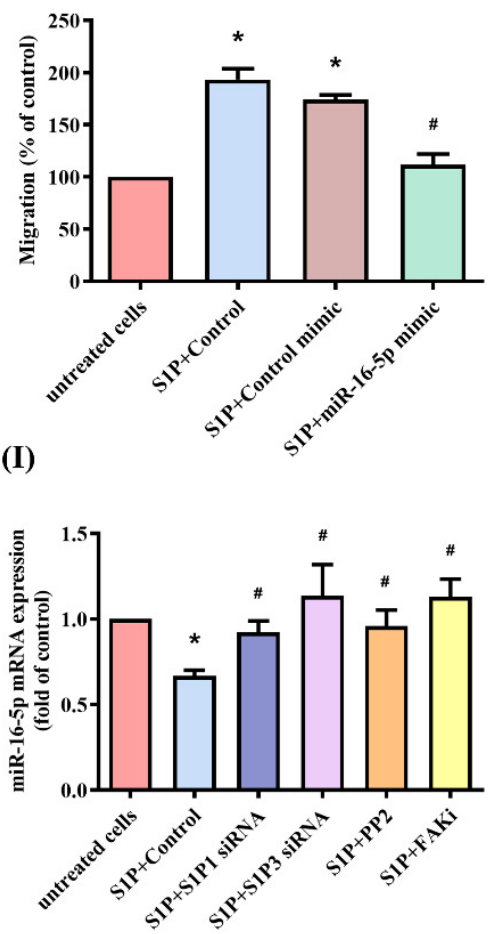

Figure 5. S1P facilitates VEGF synthesis and EPC angiogenesis via the inhibition of miR-16-5p. (A) The open-source software enabled identification of miRNAs that possibly disturb the transcription of VEGF. (B) Osteoblasts were transfected with S1P. MiR-16-5p expression was determined by the qPCR assay. $(\mathbf{C}, \mathbf{D})$ The osteoblasts were transfected with miR-16-5p mimic, then stimulated by S1P. Levels of VEGF were determined by qPCR and ELISA. (E,F) Collected CM was administered to the EPCs, and angiogenesis was quantified. (G) A schematic representation of human VEGF containing the miR-16-5p binding site. (H) The luciferase plasmids with, or without miR-16-5p mimic, were transfected into osteoblasts, before stimulating them with S1P. Measurement of luciferase activity revealed VEGF promoter activity. (I) Osteoblasts were transfected with $\mathrm{S1P}_{1}$ or $\mathrm{S1P}_{3}$ siRNA for $24 \mathrm{~h}$, or pretreated with c-Src or FAK inhibitors for $30 \mathrm{~min}$, then stimulated with S1P for $24 \mathrm{~h}$. MiR-16-5p expression was quantified by qPCR. Results are expressed as the mean \pm S.D. $(n=3) .{ }^{*} p<0.05$ versus the control; $\# p<0.05$ versus S1P alone. 

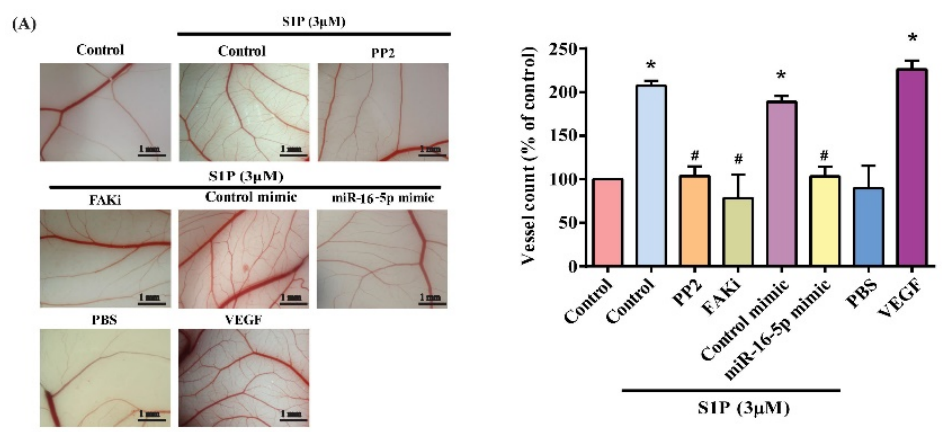

(C)
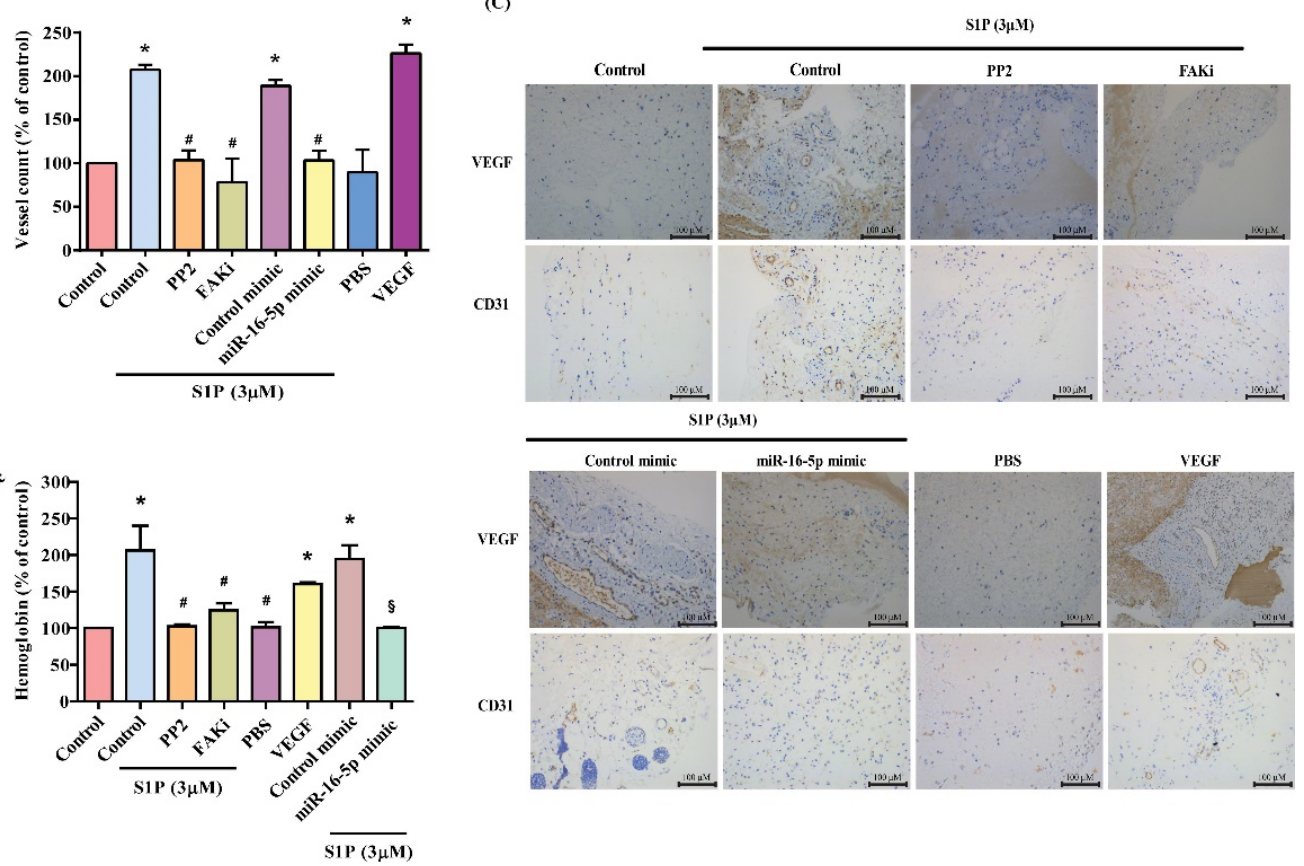

Figure 6. S1P increases angiogenesis in vivo. (A) After subjecting osteoblasts to the treatment conditions as indicated, the harvested CM was administered to 6-day-old fertilized chick embryos for 4 days. CAM images were observed by microscopy and photographed, and vessel numbers were counted manually. (B) The flanks of nude mice were subcutaneously injected with the Matrigel plugs containing the harvested CM. After 7 days, the plugs were photographed, and hemoglobin levels were evaluated. (C) CD31 and VEGF expression were detected on plug specimens by IHC staining. Results are expressed as the mean \pm S.D. $(n=3) .{ }^{*} p<0.05$ versus the control; $\# p<0.05$ versus S1P alone.

\subsection{Inhibition of S1P Reduces CIA}

SphK1 shRNA was used to validate the in vivo role of S1P. Infection of MG-63 cells with SphK1 shRNA reduced SphK1 and VEGF expression (Figure 7A). Compared with controls, CIA mice exhibited significant paw swelling that improved after administration of SphK1 shRNA (Figure 7B,C). Micro-CT imaging of the hind paws revealed that SphK1 shRNA reversed CIA-induced reductions in bone mineral density (BMD), trabecular ( $\mathrm{Tb}$ ) number and bone volume (BV) (Figure 7D-F). According to IHC staining data, levels of CD31, CD34, CD133 and VEGF expression were markedly higher in CIA mice than in controls. Notably, SphK1 shRNA treatment antagonized CD31, VEGF, CD34 and CD133 expression (Figure 6G). These results indicate that inhibiting S1P lowers EPC expression and disease activity in CIA. 
(A)

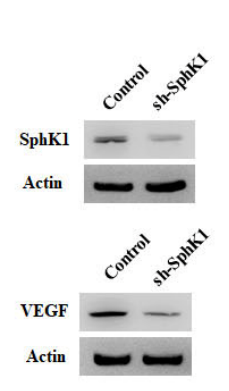

(D)

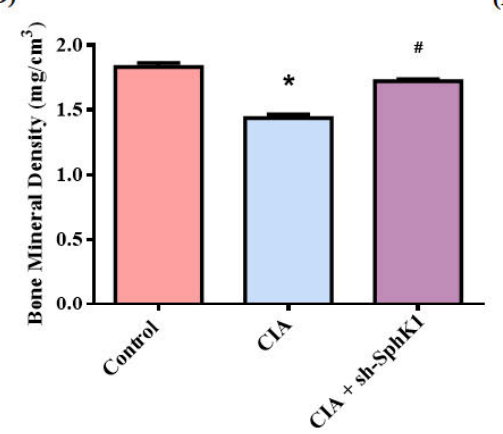

(B)

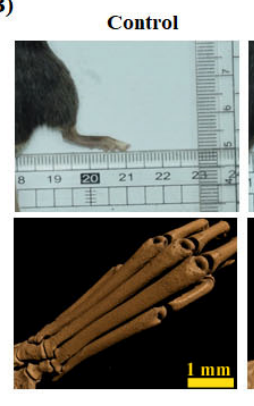

(E)

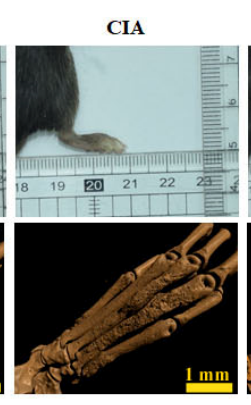

)
(C)

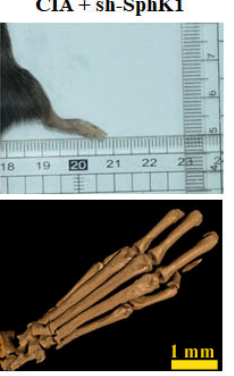

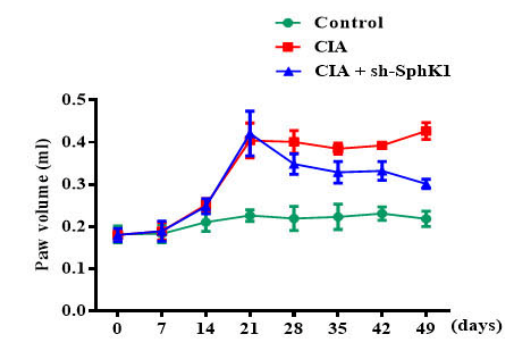

(F)

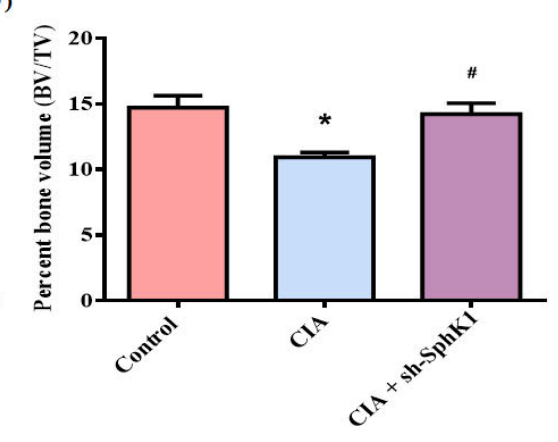

(G)
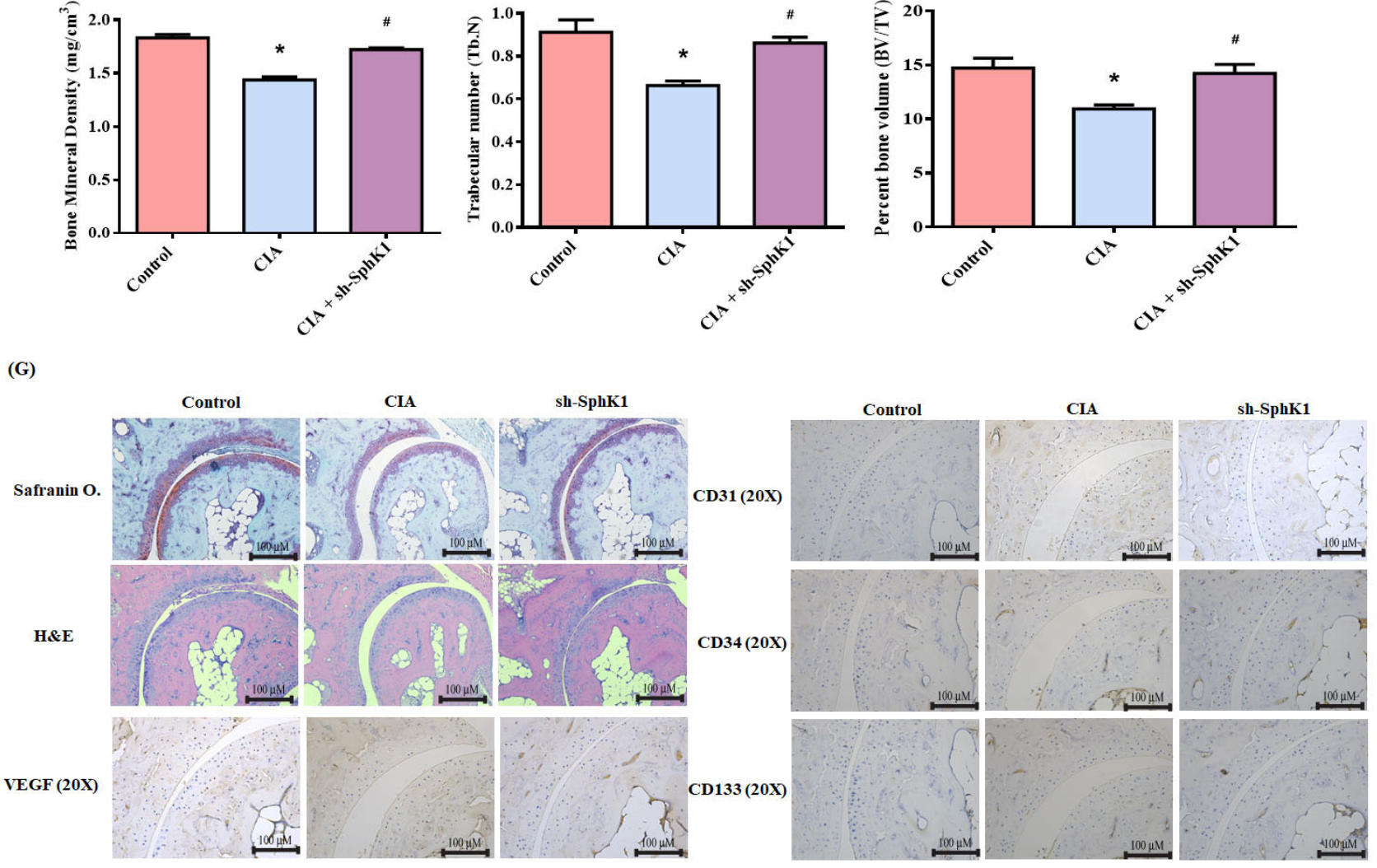

Figure 7. S1P knockdown reduces the in vivo severity of RA. (A) After infecting osteoblasts with control or SphK1 shRNA, Western blot determined SphK1 and VEGF expression. CIA mice received intra-articular injections of $\sim 7.1 \times 10^{6} \mathrm{PFU}$ SphK1 shRNA or control shRNA on day 14 and were sacrificed on day 49. (B) Representative $\mu$-CT images of the hind paws taken on day 49. (C) A digital plethysmometer quantified the amounts of hind paw swelling. (D-F) $\mu-C T$ SkyScan Software quantified BMD, trabecular numbers and bone volume. (G) Histological sections of ankle joints were stained with $\mathrm{H}$ and $\mathrm{E}$ or Safranin O/fast green, and immunostained with VEGF, CD31, CD34 and CD133. Results are expressed as the mean \pm S.D. $(n=3) .{ }^{*} p<0.05$ versus the control group; $\# p<0.05$ versus S1P alone.

\section{Discussion}

RA is well recognized for its considerable impact on synovial inflammation and joint destruction [43-45]. The development of RA relies upon pannus formation and neovascularization [1], as well as VEGF-induced stimulation of angiogenesis [6]. We have previously documented S1P-induced increases in the expression of IL- 6 and IL-1 $\beta$ in human osteoblasts [15,21]. In this study, we observed much higher S1P and VEGF expression in RA synovial fluid compared with OA samples, emphasizing the importance of S1P and VEGF in the pathogenesis of RA, which is reinforced by our evidence showing that S1P stimulates osteoblastic VEGF production and facilitates EPC angiogenesis by blocking miR-16-5p synthesis via c-Src/FAK signaling. 
EPCs also stimulate new vessel formation [2,3]. Promotion of EPC mobilization by tumor-secreted VEGF facilitates tumor development and angiogenesis [46]. EPC angiogenesis plays a vital role in RA [6,47]. EPC infiltration into joints has been reported in RA [6]. Compared with synovial fluid from healthy individuals, RA synovial fluid facilitates EPC infiltration and angiogenesis [6], indicating that EPC-dependent angiogenesis is an important step during RA progression. In this study, CM from S1P-treated osteoblasts increased EPC angiogenesis. Our CIA animal model confirmed higher levels of EPC-specific markers compared with levels in healthy controls. SphK1 shRNA inhibited S1P expression, which reduced levels of VEGF expression and EPCs, and mitigated the severity of RA. Thus, inhibition of S1P shows promise as a novel strategy in RA, reducing EPC angiogenesis and disease development.

Successful bone formation depends upon osteoblasts forming and maintaining the skeletal architecture [48,49]. Osteoblasts are critical regulators of arthritis progression [50,51]. Several proinflammatory cytokines, including IL-1 $\beta$, IL-6 and oncostatin M, are produced by osteoblasts in the joint microenvironment $[15,21]$. Osteoblast production of monocyte chemoattractant protein 1 triggers the migration and adhesion of monocytes to the RA synovial membrane, stimulating disease progression [52]. Importantly, synthesis of IL-18 and VEGF by osteoblasts promotes angiogenesis during RA [25], indicating that osteoblastmediated angiogenesis has a critical role in the development of this disease. Our cellular model revealed that S1P increases VEGF mRNA and protein expression in osteoblasts. CM from S1P-treated osteoblasts also facilitated angiogenesis in EPCs, confirming the role of osteoblast-regulated EPC angiogenesis in RA.

c-Src/FAK signaling activation is essential for regulating various cellular functions [53]. Our investigations found that c-Src and FAK inhibitors reduced S1P-enhanced VEGF expression in osteoblasts and EPC angiogenesis. This was confirmed by findings from genetic siRNA experiments demonstrating that c-Src and FAK mediate the angiogenic effects of S1P. Treatment of osteoblasts with S1P augmented c-Src and FAK phosphorylation, while c-Src inhibitor treatment inhibited S1P-promoted FAK phosphorylation. This suggests that FAK is a downstream molecule of c-Src, although FAK has been reported to be an upstream mediator of c-Src [39]. In our study, the lack of any effect from a FAK inhibitor on S1P-facilitated phosphorylation of c-Src indicates that FAK activation depends upon c-Src and that this pathway controls S1P-induced VEGF expression and EPC angiogenesis in human osteoblasts.

MiRNAs post-transcriptionally regulate gene expression [54]. In RA, aberrant miRNA expression regulates the expression of inflammatory pathways [41,42]. In this study, stimulation of osteoblasts with S1P inhibited miR-16-5p expression and transfecting them with miR-16-5p mimic antagonized S1P-promoted upregulation of VEGF expression and EPC angiogenesis. Treating the osteoblasts with c-Src and FAK inhibitors reversed S1Ppromoted inhibition of miR-16-5p expression, suggesting that S1P may increase VEGF and EPC angiogenesis by blocking miR-16-5p production via c-Src/FAK signaling.

\section{Conclusions}

In conclusion, we have determined that S1P increases osteoblastic VEGF expression and subsequently facilitates EPC angiogenesis by blocking miR-16-5p synthesis through c-Src/FAK signaling (Figure 8). The evidence supports the targeting of S1P in RA treatment regimens. 


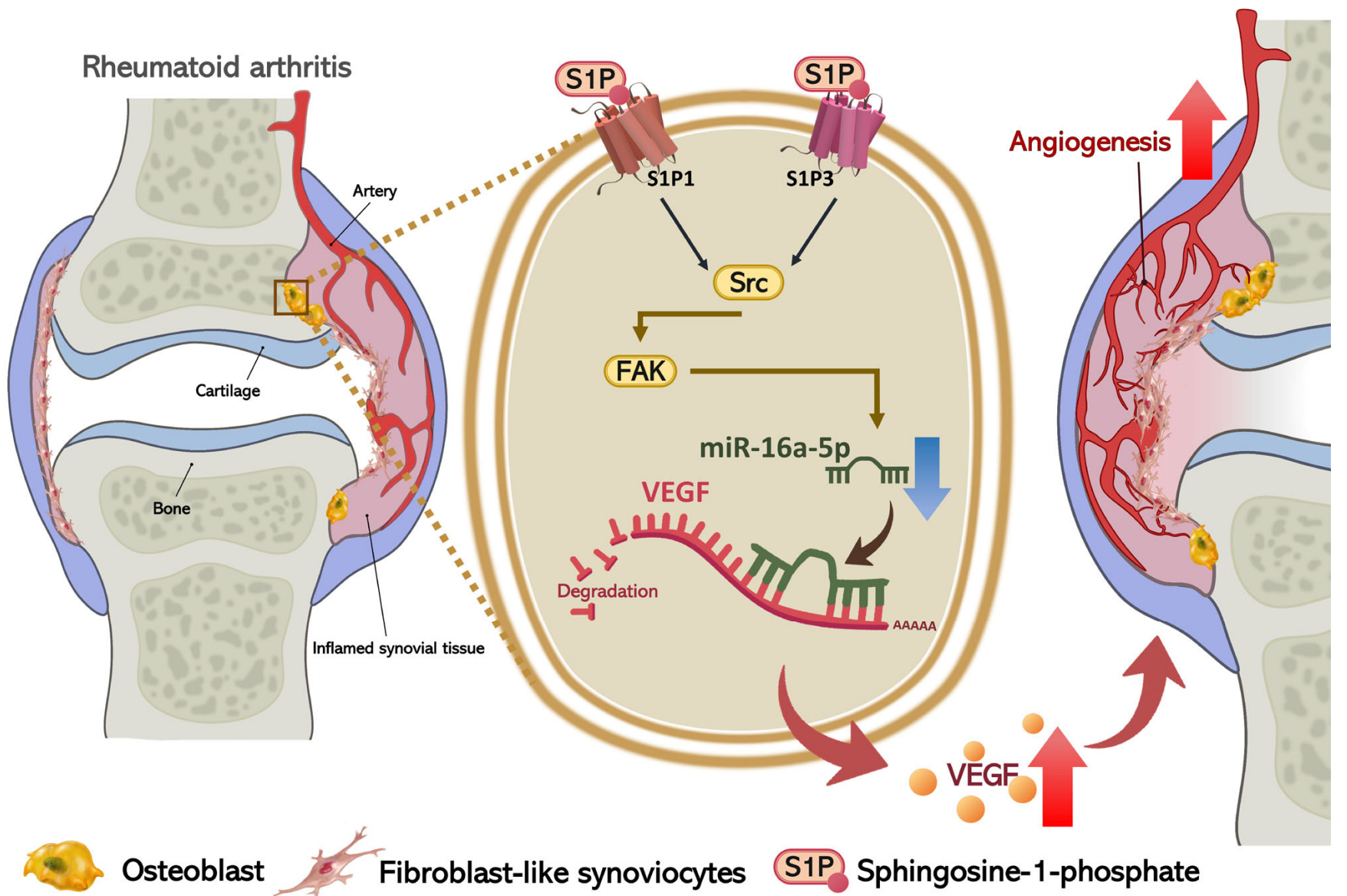

Figure 8. Schematic diagram summarizes the mechanisms of S1P-induced EPC angiogenesis during RA pathogenesis. S1P induces VEGF expression in osteoblasts by suppressing miR-16-5p expression via the S1P 1 and S1P3 receptors, and the c-Src and FAK signaling pathways, and promotes EPC angiogenesis in RA.

Author Contributions: Data curation, C.-C.H. and T.-T.T.; Formal analysis, C.-C.H., T.-T.T. and Y.-Y.L.; Investigation, C.-C.H. and T.-T.T.; Methodology, T.-T.T. and Y.-Y.L.; Project administration, C.-H.T. (Chun-Hao Tsai) and C.-H.T. (Chih-Hsin Tang); Resources, C.-C.H., S.-L.H. and S.-W.W.; Validation, T.-T.T.; Visualization, Y.-Y.L. (Yat-Yin Law); Writing-original draft, S.-C.L., Y.-Y.L. and Y.-Y.L. (Yat-Yin Law); Writing-review \& editing, C.-H.T. (Chun-Hao Tsai) and C.-H.T. (Chih-Hsin Tang). All authors have read and agreed to the published version of the manuscript.

Funding: The Ministry of Science and Technology in Taiwan (MOST 108-2314-B-039-034-MY3; MOST 108-2320-B-039-057; MOST 108-2320-B-039-065; MOST 110-2320-B-039-022-MY3) and China Medical University Hospital (DMR-110-022) provided grant support for this study.

Institutional Review Board Statement: The study protocol involving clinical samples was approved by the IRB of China Medical University Hospital (Approval No. MUH108-REC3-039). All experiments involving animals were conducted according to the ethical policies and procedures issued by the Institutional Animal Care and Use Committee of China Medical University, which approved our experiments (Approval No. 2018-102).

Informed Consent Statement: All patients were cared for in China Medical University Hospital, Taichung, Taiwan, and all patients submitted written informed consent before study participation.

Data Availability Statement: The raw data for this study are available from the corresponding authors.

Acknowledgments: We express thanks to Iona J. MacDonald from CMU for her editing of this report.

Conflicts of Interest: There are no conflicts of interest of all authors with other people or organizations that could inappropriately influence this work. 


\section{References}

1. MacDonald, I.J.; Liu, S.C.; Su, C.M.; Wang, Y.H.; Tsai, C.H.; Tang, C.H. Implications of Angiogenesis Involvement in Arthritis. Int. J. Mol. Sci. 2018, 19, 2012. [CrossRef] [PubMed]

2. Patel, J.; Donovan, P.; Khosrotehrani, K. Concise Review: Functional Definition of Endothelial Progenitor Cells: A Molecular Perspective. Stem Cells Transl. Med. 2016, 5, 1302-1306. [CrossRef] [PubMed]

3. Kiewisz, J.; Kaczmarek, M.M.; Pawlowska, A.; Kmiec, Z.; Stompor, T. Endothelial progenitor cells participation in cardiovascular and kidney diseases: A systematic review. Acta Biochim. Pol. 2016, 63, 475-482. [CrossRef]

4. Asahara, T.; Masuda, H.; Takahashi, T.; Kalka, C.; Pastore, C.; Silver, M.; Kearne, M.; Magner, M.; Isner, J.M. Bone marrow origin of endothelial progenitor cells responsible for postnatal vasculogenesis in physiological and pathological neovascularization. Circ. Res. 1999, 85, 221-228. [CrossRef]

5. Peplow, P.V. Influence of growth factors and cytokines on angiogenic function of endothelial progenitor cells: A review of in vitro human studies. Growth Factors 2014, 32, 83-116. [CrossRef]

6. Su, C.M.; Hsu, C.J.; Tsai, C.H.; Huang, C.Y.; Wang, S.W.; Tang, C.H. Resistin Promotes Angiogenesis in Endothelial Progenitor Cells through Inhibition of MicroRNA206: Potential Implications for Rheumatoid Arthritis. Stem Cells 2015, 33, $2243-2255$. [CrossRef] [PubMed]

7. Chen, C.Y.; Su, C.M.; Hsu, C.J.; Huang, C.C.; Wang, S.W.; Liu, S.C.; Chen, W.C.; Fuh, L.J.; Tang, C.H. CCN1 Promotes VEGF Production in Osteoblasts and Induces Endothelial Progenitor Cell Angiogenesis by Inhibiting miR-126 Expression in Rheumatoid Arthritis. J. Bone Miner. Res. 2017, 32, 34-45. [CrossRef]

8. Ryu, Y.; Takuwa, N.; Sugimoto, N.; Sakurada, S.; Usui, S.; Okamoto, H.; Matsui, O.; Takuwa, Y. Sphingosine-1-phosphate, a platelet-derived lysophospholipid mediator, negatively regulates cellular Rac activity and cell migration in vascular smooth muscle cells. Circ. Res. 2002, 90, 325-332. [CrossRef] [PubMed]

9. Meacci, E.; Garcia-Gil, M. S1P/S1P Receptor Signaling in Neuromuscolar Disorders. Int. J. Mol. Sci. 2019, 20, 6364. [CrossRef] [PubMed]

10. Mascall, K.S.; Small, G.R.; Gibson, G.; Nixon, G.F. Sphingosine-1-phosphate-induced release of TIMP-2 from vascular smooth muscle cells inhibits angiogenesis. J. Cell Sci. 2012, 125, 2267-2275. [CrossRef] [PubMed]

11. Tsai, C.H.; Yang, D.Y.; Lin, C.Y.; Chen, T.M.; Tang, C.H.; Huang, Y.L. Sphingosine-1-phosphate suppresses chondrosarcoma metastasis by upregulation of tissue inhibitor of metalloproteinase 3 through suppressing miR-101 expression. Mol. Oncol. 2017, 11, 1380-1398. [CrossRef]

12. Xiao, L.; Zhou, Y.; Friis, T.; Beagley, K.; Xiao, Y. S1P-S1PR1 Signaling: The "Sphinx" in Osteoimmunology. Front. Immunol. 2019, 10, 1409. [CrossRef] [PubMed]

13. Inoue, T.; Kohno, M.; Nagahara, H.; Murakami, K.; Sagawa, T.; Kasahara, A.; Kaneshita, S.; Kida, T.; Fujioka, K.; Wada, M.; et al. Upregulation of sphingosine-1-phosphate receptor 3 on fibroblast-like synoviocytes is associated with the development of collagen-induced arthritis via increased interleukin-6 production. PLoS ONE 2019, 14, e0218090. [CrossRef]

14. Sun, M.; Deng, R.; Wang, Y.; Wu, H.; Zhang, Z.; Bu, Y.; Zhang, H. Sphingosine kinase 1/sphingosine 1-phosphate/sphingosine 1-phosphate receptor 1 pathway: A novel target of geniposide to inhibit angiogenesis. Life Sci. 2020, 256, 117988. [CrossRef] [PubMed]

15. Hu, S.L.; Huang, C.C.; Tzeng, T.T.; Liu, S.C.; Tsai, C.H.; Fong, Y.C.; Tang, C.H. S1P promotes IL-6 expression in osteoblasts through the PI3K, MEK/ERK and NF-kappaB signaling pathways. Int. J. Med. Sci. 2020, 17, 1207-1214. [CrossRef] [PubMed]

16. Hu, S.L.; Chang, A.C.; Huang, C.C.; Tsai, C.H.; Lin, C.C.; Tang, C.H. Myostatin Promotes Interleukin-1beta Expression in Rheumatoid Arthritis Synovial Fibroblasts through Inhibition of miR-21-5p. Front. Immunol. 2017, 8, 1747. [CrossRef]

17. Su, C.M.; Lee, W.L.; Hsu, C.J.; Lu, T.T.; Wang, L.H.; Xu, G.H.; Tang, C.H. Adiponectin Induces Oncostatin M Expression in Osteoblasts through the PI3K/Akt Signaling Pathway. Int. J. Mol. Sci. 2015, 17, 29. [CrossRef] [PubMed]

18. Su, C.M.; Chiang, Y.C.; Huang, C.Y.; Hsu, C.J.; Fong, Y.C.; Tang, C.H. Osteopontin Promotes Oncostatin M Production in Human Osteoblasts: Implication of Rheumatoid Arthritis Therapy. J. Immunol. 2015, 195, 3355-3364. [CrossRef] [PubMed]

19. Tsai, C.H.; Liu, S.C.; Wang, Y.H.; Su, C.M.; Huang, C.C.; Hsu, C.J.; Tang, C.H. Osteopontin inhibition of miR-129-3p enhances IL-17 expression and monocyte migration in rheumatoid arthritis. Biochim. Biophys. Acta Gen. Subj. 2017, 1861, 15-22. [CrossRef]

20. Kitano, M.; Hla, T.; Sekiguchi, M.; Kawahito, Y.; Yoshimura, R.; Miyazawa, K.; Iwasaki, T.; Sano, H.; Saba, J.D.; Tam, Y.Y Sphingosine 1-phosphate/sphingosine 1-phosphate receptor 1 signaling in rheumatoid synovium: Regulation of synovial proliferation and inflammatory gene expression. Arthritis Rheumatol. 2006, 54, 742-753. [CrossRef] [PubMed]

21. Hu, S.L.; Huang, C.C.; Tseng, T.T.; Liu, S.C.; Tsai, C.H.; Fong, Y.C.; Tang, C.H. S1P facilitates IL-1beta production in osteoblasts via the JAK and STAT3 signaling pathways. Environ. Toxicol. 2020, 35, 991-997. [CrossRef] [PubMed]

22. Cunningham, C.C.; Wade, S.; Floudas, A.; Orr, C.; McGarry, T.; Wade, S.; Cregan, S.; Fearon, U.; Veale, D.J. Serum miRNA Signature in Rheumatoid Arthritis and "At-Risk Individuals". Front. Immunol. 2021, 12, 633201. [CrossRef] [PubMed]

23. Wang, L.; Song, G.; Zheng, Y.; Wang, D.; Dong, H.; Pan, J.; Chang, X. miR-573 is a negative regulator in the pathogenesis of rheumatoid arthritis. Cell. Mol. Immunol. 2016, 13, 839-849. [CrossRef]

24. Law, Y.Y.; Lee, W.F.; Hsu, C.J.; Lin, Y.Y.; Tsai, C.H.; Huang, C.C.; Wu, M.H.; Tang, C.H.; Liu, J.F. miR-let-7c-5p and miR-149-5p inhibit proinflammatory cytokine production in osteoarthritis and rheumatoid arthritis synovial fibroblasts. Aging 2021, 13, 17227-17236. [CrossRef] 
25. Li, T.M.; Liu, S.C.; Huang, Y.H.; Huang, C.C.; Hsu, C.J.; Tsai, C.H.; Wang, S.W.; Tang, C.H. YKL-40-Induced Inhibition of miR-590-3p Promotes Interleukin-18 Expression and Angiogenesis of Endothelial Progenitor Cells. Int. J. Mol. Sci. 2017, 18, 920. [CrossRef] [PubMed]

26. Degagne, E.; Pandurangan, A.; Bandhuvula, P.; Kumar, A.; Eltanawy, A.; Zhang, M.; Yoshinaga, Y.; Nefedov, M.; de Jong, P.J.; Fong, L.G.; et al. Sphingosine-1-phosphate lyase downregulation promotes colon carcinogenesis through STAT3-activated microRNAs. J. Clin. Investig. 2014, 124, 5368-5384. [CrossRef] [PubMed]

27. Ji, X.; Yang, L.; Zhang, Z.; Zhang, K.; Chang, N.; Zhou, X.; Hou, L.; Yang, L.; Li, L. Sphingosine 1-phosphate/microRNA-1249$5 \mathrm{p} / \mathrm{MCP}-1$ axis is involved in macrophage-associated inflammation in fatty liver injury in mice. Eur. J. Immunol. 2020, 50, 1746-1756. [CrossRef] [PubMed]

28. Chen, A.W.; Lu, C.; Lin, B.; Xian, S.; Huang, F.; Wu, Y.; Zeng, Z. Inhibition of miR-155-5p attenuates the valvular damage induced by rheumatic heart disease. Int. J. Mol. Med. 2020, 45, 20. [CrossRef]

29. Wang, S.W.; Liu, S.C.; Sun, H.L.; Huang, T.Y.; Chan, C.H.; Yang, C.Y.; Yeh, H.I.; Huang, Y.L.; Chou, W.Y.; Lin, Y.M.; et al. CCL5/CCR5 axis induces vascular endothelial growth factor-mediated tumor angiogenesis in human osteosarcoma microenvironment. Carcinogenesis 2015, 36, 104-114. [CrossRef] [PubMed]

30. Wu, M.H.; Huang, C.Y.; Lin, J.A.; Wang, S.W.; Peng, C.Y.; Cheng, H.C.; Tang, C.H. Endothelin-1 promotes vascular endothelial growth factor-dependent angiogenesis in human chondrosarcoma cells. Oncogene 2014, 33, 1725-1735. [CrossRef] [PubMed]

31. Lee, H.P.; Chen, P.C.; Wang, S.W.; Fong, Y.C.; Tsai, C.H.; Tsai, F.J.; Chung, J.G.; Huang, C.Y.; Yang, J.S.; Hsu, Y.M.; et al. Plumbagin suppresses endothelial progenitor cell-related angiogenesis in vitro and in vivo. J. Funct. Foods 2019, 52, 537-544. [CrossRef]

32. Lee, H.P.; Wang, S.W.; Wu, Y.C.; Tsai, C.H.; Tsai, F.J.; Chung, J.G.; Huang, C.Y.; Yang, J.S.; Hsu, Y.M.; Yin, M.C.; et al. Glucocerebroside reduces endothelial progenitor cell-induced angiogenesis. Food Agric. Immunol. 2019, 30, 1033-1045. [CrossRef]

33. Liu, J.F.; Lee, C.W.; Tsai, M.H.; Tang, C.H.; Chen, P.C.; Lin, L.W.; Lin, C.Y.; Lu, C.H.; Lin, Y.F.; Yang, S.H.; et al. Thrombospondin 2 promotes tumor metastasis by inducing matrix metalloproteinase-13 production in lung cancer cells. Biochem. Pharmacol. 2018, 155, 537-546. [CrossRef] [PubMed]

34. Huang, C.C.; Chiou, C.H.; Liu, S.C.; Hu, S.L.; Su, C.M.; Tsai, C.H.; Tang, C.H. Melatonin attenuates TNF-alpha and IL-1beta expression in synovial fibroblasts and diminishes cartilage degradation: Implications for the treatment of rheumatoid arthritis. J. Pineal Res. 2019, 66, e12560. [CrossRef] [PubMed]

35. Liu, S.C.; Tsai, C.H.; Wu, T.Y.; Tsai, C.H.; Tsai, F.J.; Chung, J.G.; Huang, C.Y.; Yang, J.S.; Hsu, Y.M.; Yin, M.C.; et al. Soya-cerebroside reduces IL-1 beta-induced MMP-1 production in chondrocytes and inhibits cartilage degradation: Implications for the treatment of osteoarthritis. Food Agric. Immunol. 2019, 30, 620-632. [CrossRef]

36. Wang, M.; Chao, C.C.; Chen, P.C.; Liu, P.I.; Yang, Y.C.; Su, C.M.; Huang, W.C.; Tang, C.H. Thrombospondin enhances RANKLdependent osteoclastogenesis and facilitates lung cancer bone metastasis. Biochem. Pharmacol. 2019, 166, 23-32. [CrossRef] [PubMed]

37. Liu, S.C.; Chuang, S.M.; Hsu, C.J.; Tsai, C.H.; Wang, S.W.; Tang, C.H. CTGF increases vascular endothelial growth factor-dependent angiogenesis in human synovial fibroblasts by increasing miR-210 expression. Cell Death Dis. 2014, 5, e1485. [CrossRef] [PubMed]

38. Chien, S.Y.; Tsai, C.H.; Liu, S.C.; Huang, C.C.; Lin, T.H.; Yang, Y.Z.; Tang, C.H. Noggin Inhibits IL-1beta and BMP-2 Expression, and Attenuates Cartilage Degeneration and Subchondral Bone Destruction in Experimental Osteoarthritis. Cells 2020, 9, 927. [CrossRef] [PubMed]

39. Wang, C.Q.; Huang, Y.W.; Wang, S.W.; Huang, Y.L.; Tsai, C.H.; Zhao, Y.M.; Huang, B.F.; Xu, G.H.; Fong, Y.C.; Tang, C.H. Amphiregulin enhances VEGF-A production in human chondrosarcoma cells and promotes angiogenesis by inhibiting miR-206 via FAK/c-Src/PKCdelta pathway. Cancer Lett. 2017, 385, 261-270. [CrossRef]

40. Zhang, L.; Dong, Y.; Wang, Y.; Hu, W.; Dong, S.; Chen, Y. Sphingosine-1-phosphate (S1P) receptors: Promising drug targets for treating bone-related diseases. J. Cell. Mol. Med. 2020, 24, 4389-4401. [CrossRef] [PubMed]

41. Zhang, L.; Wu, H.; Zhao, M.; Chang, C.; Lu, Q. Clinical significance of miRNAs in autoimmunity. J. Autoimmun. 2020, 109, 102438. [CrossRef]

42. Wang, J.; Yan, S.; Yang, J.; Lu, H.; Xu, D.; Wang, Z. Non-coding RNAs in Rheumatoid Arthritis: From Bench to Bedside. Front. Immunol. 2019, 10, 3129. [CrossRef]

43. McInnes, I.B.; Schett, G. The pathogenesis of rheumatoid arthritis. N. Engl. J. Med. 2011, 365, 2205-2219. [CrossRef] [PubMed]

44. Smolen, J.S.; Aletaha, D.; McInnes, I.B. Rheumatoid arthritis. Lancet 2016, 388, 2023-2038. [CrossRef]

45. Catrina, A.I.; Svensson, C.I.; Malmstrom, V.; Schett, G.; Klareskog, L. Mechanisms leading from systemic autoimmunity to joint-specific disease in rheumatoid arthritis. Nat. Rev. Rheumatol. 2017, 13, 79-86. [CrossRef] [PubMed]

46. Peters, B.A.; Diaz, L.A.; Polyak, K.; Meszler, L.; Romans, K.; Guinan, E.C.; Antin, J.H.; Myerson, D.; Hamilton, S.R.; Vogelstein, B.; et al. Contribution of bone marrow-derived endothelial cells to human tumor vasculature. Nat. Med. 2005, 11, 261-262. [CrossRef] [PubMed]

47. Chien, S.Y.; Huang, C.Y.; Tsai, C.H.; Wang, S.W.; Lin, Y.M.; Tang, C.H. Interleukin-1beta induces fibroblast growth factor 2 expression and subsequently promotes endothelial progenitor cell angiogenesis in chondrocytes. Clin. Sci. (Lond.) 2016, 130, 667-681. [CrossRef]

48. Seeman, E.; Martin, T.J. Antiresorptive and anabolic agents in the prevention and reversal of bone fragility. Nat. Rev. Rheumatol. 2019, 15, 225-236. [CrossRef] [PubMed]

49. Kim, B.J.; Koh, J.M. Coupling factors involved in preserving bone balance. Cell. Mol. Life Sci. 2019, 76, 1243-1253. [CrossRef] 
50. Huang, C.Y.; Chen, S.Y.; Tsai, H.C.; Hsu, H.C.; Tang, C.H. Thrombin induces epidermal growth factor receptor transactivation and CCL2 expression in human osteoblasts. Arthritis Rheumatol. 2012, 64, 3344-3354. [CrossRef]

51. Tang, C.H.; Hsu, C.J.; Fong, Y.C. The CCL5/CCR5 axis promotes interleukin-6 production in human synovial fibroblasts. Arthritis Rheumatol. 2010, 62, 3615-3624. [CrossRef] [PubMed]

52. Chen, C.Y.; Fuh, L.J.; Huang, C.C.; Hsu, C.J.; Su, C.M.; Liu, S.C.; Lin, Y.M.; Tang, C.H. Enhancement of CCL2 expression and monocyte migration by CCN1 in osteoblasts through inhibiting miR-518a-5p: Implication of rheumatoid arthritis therapy. Sci. Rep. 2017, 7, 421. [CrossRef] [PubMed]

53. Vlaeminck-Guillem, V.; Gillet, G.; Rimokh, R. SRC: Marker or actor in prostate cancer aggressiveness. Front. Oncol. 2014, 4, 222. [CrossRef] [PubMed]

54. Nugent, M. MicroRNAs: Exploring new horizons in osteoarthritis. Osteoarthr. Cartil. 2016, 24, 573-580. [CrossRef] 